\title{
LAS INDUSTRIAS DE SALAZÓN EN EL NORTE DE LA PENÍNSULA IBÉRICA EN ÉPOCA ROMANA. NUEVAS APORTACIONES
}

\author{
POR \\ CARMEN FERNÁNDEZ OCHOA Y JULIO MARTINEZZ MAGANTO \\ Departamento de Prehistoria y Arqueologia. Universidad Autonoma de Madrid
}

\section{RESUMEN}

A partir del descubrimiento de una factoría de salazones en la ciudad de Gijón (Asturias), se realiza un estudio analitico de los testimonios de estas industrias en el Norte y Noroeste de la Peninsula Ibérica en época romana. En general esta zona geográfica no está incluida en los estudios peninsulares sobre el tema.

\section{SUMMARY}

From the discovery of a salted fish products factory in Gijón (Asturias) we have developed an analytical study of the presence of these industries in the N. and N.W. of the Iberian Peninsula in Roman times. This area has not been included in the studies carried out on this subject so far.

\section{INTRODUCCIÓN}

El avance de la investigación arqueológica en el N. y NO. peninsular en los últimos años, ha permitido el descubrimiento y el reestudio de algunos restos arqueológicos de cierta singularidad como son los de las industrias dedicadas a la explotación de los recursos maritimos en las zonas atlánticas y cantábricas de Hispania.

Estas regiones han estado ausentes de las grandes síntesis (Ponsich, 1988; Curtis, 1991) y de los mapas de distribución al uso (Jiménez Contreras, 1986) a pesar de que en los años cuarenta, algún autor había certificado la presencia de establecimientos salazoneros en la costa cantábrica de Galicia (Maciñeira, 1947; Vázquez Seijas, 1952). En nuestra opinión, la ausencia de excavaciones en enclaves costeros romanos en todo el N. y NO. hispano, problema en vías de solución desde hace menos de una década, ha sido el responsable final de este silencio bibliográfico.
El hallazgo casual de los restos de una factoria de salazones junto al puerto de la ciudad de Gijón, excavada en 1991 por uno de nosotros (Fernández Ochoa, 1993), nos ha impulsado a replantear este tema para ofrecer una visión conjunta del mismo y establecer las relaciones pertinentes con las regiones atlánticas de la Gallia y de Britannia. Es nuestra intención contribuir al incremento de las evidencias que sobre el proceso romanizador del N. y N.O. peninsular arrojan restos arqueológicos de diversa índole y, en este caso concreto, los que se relacionan con la transformación de la pesca y sus derivados.

En primer lugar, analizaremos las características de la costa (Oceanus Atlanticus/Mare Cantabricum) y las posibilidades de capturas que ofrecen estos mares; a continuación estableceremos el catálogo de los lugares con restos identificables como industrias salazoneras partiendo de las Rías Bajas y continuando, en sentido Este, a lo largo de la costa cantábrica, con el fin de extraer las conclusiones oportunas. Por último, trataremos de aproximarnos a una definición del alcance de estas producciones en el conjunto de los "finisterres atlánticos» del Imperio.

\section{CONDICIONANTES GEOGRÁFICOS}

La zona geográfica que se pretende tratar en estas páginas engloba dos áreas costeras con características geomorfológicas y climatológicas distintas: la costa atlántica gallega (especialmente en torno a las Rías Bajas) y la costa cantábrica. Ambos tramos costeros se encuentran separados por el Cabo de Ortegal, punto clave para situar divisorias de las 
distintas corrientes de aguas, asi como punto de inflexion en la dirección de los vientos (Maciñeira, 1933, 220).

La costa atlätica gallega (Nonn, 1966: Naveiro, 1991. 115 y ss.) se caracteriza por una configuración sinuosa. con numerosas bahias naturales y rias, tradicionalmente aprovechadas para instalar centros portuarios, debido a sus excelentes condiciones de navegabilidad y refugio frente a vientos, además de facilitar itinerarios maritimo-fluviales de penetración hacia el interior. Sin embargo, existen algunos inconvenientes, como la vulnerabilidad de las rias frente a fuertes mareas o la presencia de arrecifes, cuya peligrosidad se incrementa con la acción de vientos y corrientes.

Por su parte, el tramo costero cantábrico presenta una tendencia rectilinea (Iglesias y Muñiz, 1992. 51) cuyo origen se encuentra en la propia linealidad de las estructuras tectónicas mayores (gran falla norpirenaica) que afectan a los materiales de nivel cortical. Esta configuración, unida a las continuas plataformas de abrasión determina una plataforma continental estrecha, caracteristica en la zona asturiana (Flor, 1991, 37). Los sectores de costas de inmersión frecuentes en esta zona implican la exis- tencia de rias vivas, siendo un magnífico ejemplo de ello la costa vasca (Esteban. 1990a, 342) y la asturiana (Flor, 1991). En ambos casos se produce un fenomeno paralelo al de la costa gallega: las rias favorecen el acceso hacia el interior asi como la ubicación de puertos fluviales de importante actividad económica para la zona.

Las corrientes marinas locales son de excepcional importancia ya que, no sólo favorecen o dificultan el tráfico naval, sino que, en cierto modo, condicionan el flujo de diversas especies marinas, de importancia capital en las industrias de salazón.

Es muy probable que aprovechando este tipo de corrientes existieran una serie de rutas, ya desde época prerromana, que costearan el Atlántico y el Cantábrico. El origen de estas rutas, en época romana. habria de situarse seguramente, en las principales metrópolis exportadoras béticas, como Gades (Plinio, II, 67).

El efecto de las corrientes, se modifica en función de los vientos costeros existentes, cuyo soplo puede favorecer o dificultar la navegación (Rouge. 1966,34 y ss.) y, por tanto, la ubicación de centros industriales $y / o$ portuarios.

En este sentido, es significativa la importancia

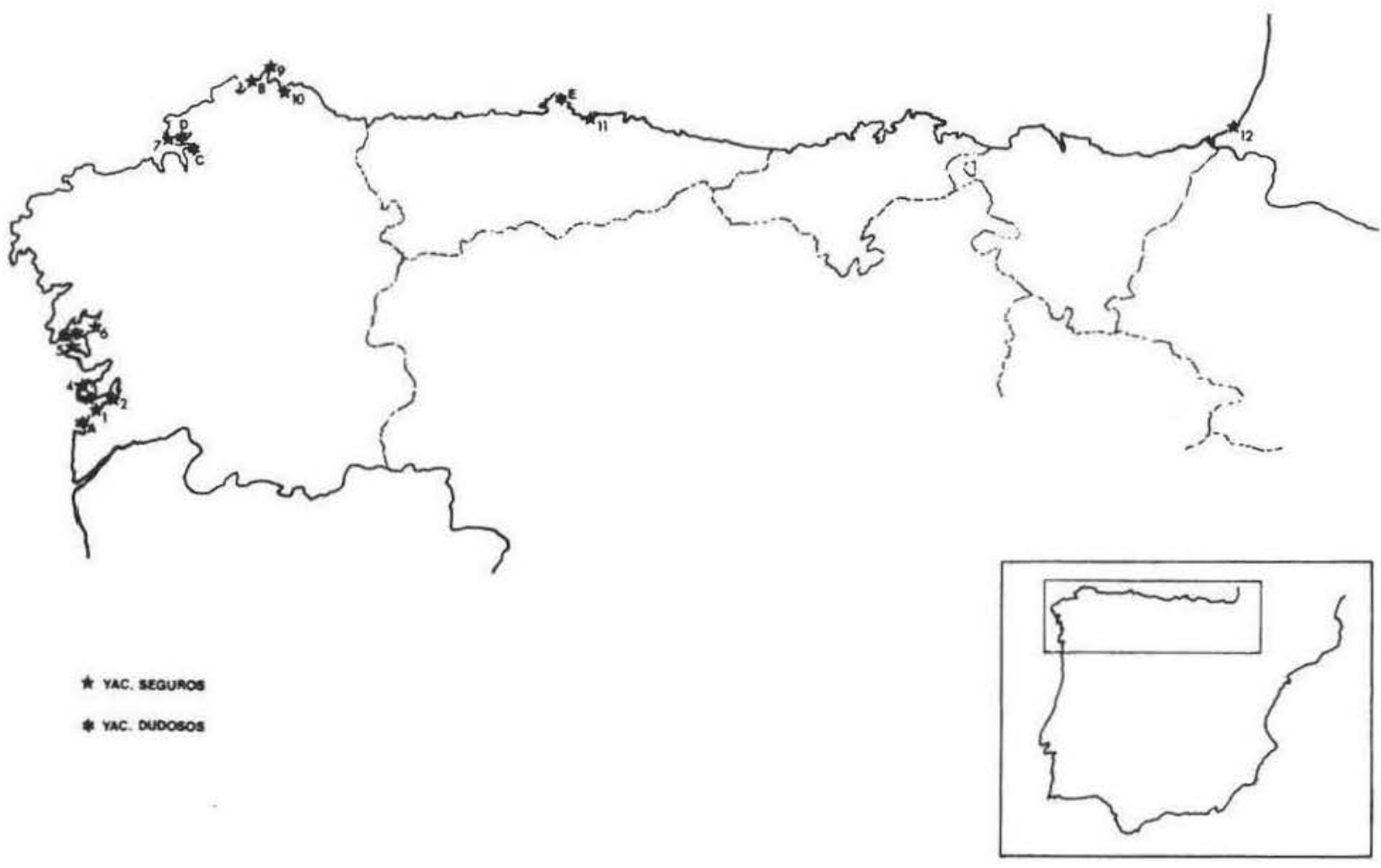

Figura 1.-Dispersión geográfica de las industrias de salazón romanas en el N. y N.O. de la Península Ibérica. 1. Alcabre: 2. Vilar; 3. Igresiña; 4. La Barra (Hio); 5. Adro-Vello; 6. Villagarcia; 7. Cariño; 8. Espasante; 9. Bares; 10. Area; 11. Gijón: 12. Guèthary. A. Panxón; B. Nasos; C. Centroña; D. Noville; E. Bañugues. 
de cabos o promontorios y su protagonismo en el régimen de los vientos. Efectivamente. los cabos se comportan como murallas naturales ante el efecto de determinados vientos, cuya potencia y peligrosidad se hace patente al sobrepasar la proteccion ofrecida por estos accidentes. Asi pues, no debe extranaar la frecuente asociación que se produce entre los cabos y los núcleos de actividad económica que. generalmente, se ubican apovechando la protección natural que aquéllos brindan, como pone de relieve la distribución de industrias salazoneras.

Por tanto, como resumen general, a pesar de las diferencias existentes entre ambos tramos costeros. existen notables coincidencias en cuanto a los condicionantes geográficos que van a tener un peso importante en la ubicación de núcleos económicos: puertos, villae, y centros de procesamiento del pescado.

\section{CATÁLOGO}

\section{GALICIA}

Si consideramos las fuentes arqueológicas e historiográficas disponibles, Galicia es la región del N.O. donde es posible constatar, de modo más fehaciente, la presencia de instalaciones orientadas a la elaboración del pescado. El hallazgo de numerosas "piletas" para salazón en distintos yacimientos romanos o romanizados, responde a una tradición pesquera anterior, ya constatada en los núcleos castreños (Vázquez Varela, 1979; Pereira, 1983, 154 y ss), que tiene su continuidad en época medieval y moderna (Rodriguez Colmenero, 1977, 185; Ferreira, 1988, espec. 58 y ss. y 93 y ss.). Los principales centros donde se realizaron actividades de transformación del pescado en época romana son:

\section{PONTEVEDRA}

\section{Alcabre (Fig. 1,1)}

Yacimiento recientemente descubierto sobre el que existen escasos datos. En la actualidad se da por segura la existencia de un núcleo salazonero en este punto del litoral vigués (Naveiro y Pérez Losada, 1992, 65, n.12), aunque, por el momento, no se dispone de datos concretos acerca de instalaciones o de materiales arqueológicos asociados a las mismas.

\section{l'ilar (Fig. 1.2)}

Considerado un centro salazonero por diversos autores (Lomba, 1987, 172). investigaciones actualizadas manifiestan serias dudas sobre la existencia de dicha industria en este yacimiento (Naveiro y Pérez Losada, 1992, 65, n. 12). Por otra parte, no contamos. al menos de forma concluyente, con ningún dato material en este sentido (Acuña, 1980, 46). A la espera de datos más concretos optamos por incluir, con ciertas reservas, este yacimiento en el censo de tales industrias.

\section{Igresiña-Nerga (Fig. 1,3)}

Este yacimiento arqueológico, situado en las cercanias de Cangas del Morrazo, fue descubierto por J. Suárez, colaborador del Museo de Pontevedra (de La Peña, 1984, n. 6). La extracción de áridos en la zona permitió sacar a la luz la existencia de piletas romanas, que se han asociado a la producción de conservas del pescado.

\section{La Burra (Hio, Cangas) (Fig. 1,4)}

En el extremo occidental de la península del Morrazo, se encuentra la parroquia de Hío. En las inmediaciones de este lugar, en la zona del arenal de la Barra, fueron localizados... «cuatro lagares de salazón dispuestos en bloques fabricados con argamasa de tipo romano" (Millán, 1978, 11). No disponemos de ningún dato de mayor entidad respecto a las dimensiones, naturaleza o disposición de estas estructuras. Este descubrimiento, efectuado por E. y J. M. "Massó, con ocasión de unas prospecciones en 1963, presenta aspectos tan interesantes como el revestimiento de estas piletas, realizado con sucesivas capas de opus signinum. Por otra parte, en esa misma zona existen restos materiales de filiación romana (tegulae, probables altares rituales...), quizá vinculado a la existencia de alguna villa, así como un asentamiento castreño en el cercano monte Facho (Bouza, Álvarez y Masso, 1971, 65 y ss.).

En un artículo sobre este yacimiento, los excavadores manifestaban abiertamente: «...sin que se advierta en ellas (playas y rocas cercanas) restos de construcciones que puedan vincularse con un embarcadero o tanques de salazón.,.) (Fariña, de Lapeña y Sierra, 1975, 177). Por lo tanto, nos encontramos ante noticias contradictorias y hasta cierto punto imprecisas que invitan a reconsiderar la existencia de la posible factoría para la elaboración del pescado (Lomba, 1987, 172). 


\section{Adre liello-() Growe (tig. 1.5)}

Las caracteristicas que presenta este yacimiento. excavado por F. (arro, son concluyentes respecto al desarrollo de una actividad orientada a la elaboración industrial del pescado. La campaña de excavación de 1987, puso de relieve la existencia de un pileta con revoco (Carro, 1987, 90) cuya funcionalidad queda esclarecida por el propio excavador: «....se trata, en realidade, dunha cuba para producir salgadura de peixe, destino evidenciado porque, ó baldeirala totalmente do entullo que a enchia, apareceu, sobre o seu piso, unha capa uniforme de aproximadamente $+/-20 \mathrm{cms}$. de espesor, constituida por escamas e pezas esqueléticas de peixes (última "camada" de salgadura)" (Carro, 1991, 94). A través de la excavación del conjunto ha sido posible localizar tres cetaria, dispuestos de forma paralela $y$, asociados a ellos, se han localizado, asimismo, restos de cápridos. Se trata de tres piletas de aprox. $1,5 \times 1,5 \times 1,5 \mathrm{~ms}$., que totalizan una producción de $10,12 \mathrm{~m}^{3}$ de volumen.

La excavación de este núcleo parece indicar que estas piletas forman parte de un yacimiento indeterminado, pero de cronología anterior a la villa tardía de los siglos III-IV d.C., cuyos restos se superponen estratigráficamente al horizonte de los cetaria. Quizá futuros trabajos arqueológicos, especialmente en torno a las dos últimas piletas exhumadas, permitan definir mejor la orientación económica de yacimiento.

\section{Villagarcia de Arosa (Fig. 1,6)}

Posiblemente se trate de unas estructuras (piletas) vinculadas al vecino Castro de Alobre (Bouza,
1957. 79: Maciñeira, 1947, n.52), en cuyo caso no es improbable, la existencia de dos momentos en su construcción/utilización; uno en época prerromana, cuyo origen se sitúa en un momento no determinado, $y$ otro en fase romana, cuyo periodo final se sitúa en torno al siglo N d.C.

El descubrimiento de dichos restos acontece como consecuencia de unas obras realizadas en el puerto moderno de Villagarcia de Arosa (1921). En 1938 se descubren varias piletas cuya forma y caracteristicas constructivas parecen idénticas a las utilizadas para las salazones de pescado (Vázquez Seijas, 1952, 114). Especialmente importante es el empleo de un revoco de opus signinum, constante repetida en otros yacimientos análogos cercanos.

\section{LA CORUÑA}

\section{Cariño (Fig. 1,7 y 2)}

Interesante hallazgo, situado en la Ría del Ferrol. La información sobre este yacimiento es minima, aunque la reconstrucción que aporta J. L. Naveiro (figura 2) en la reciente publicación de su tesis doctoral (Naveiro, 1991, 103, fig. 23 en p. 104), pone de relieve la existencia de unos cetaria (al menos siete) que podrian estar cubiertos por una techumbre de una sola vertiente. Este sistema de cubrición ha sido largamente constatado en otras instalaciones salazoneras en yacimientos andaluces y norteafricanos (Ponsich, 1988, 81).

Trabajos posteriores de J. L. Naviero no hacen mención alguna a dicho yacimiento (Naveiro y Pérez Losada, 1992), si bien el dibujo aportado anterior-

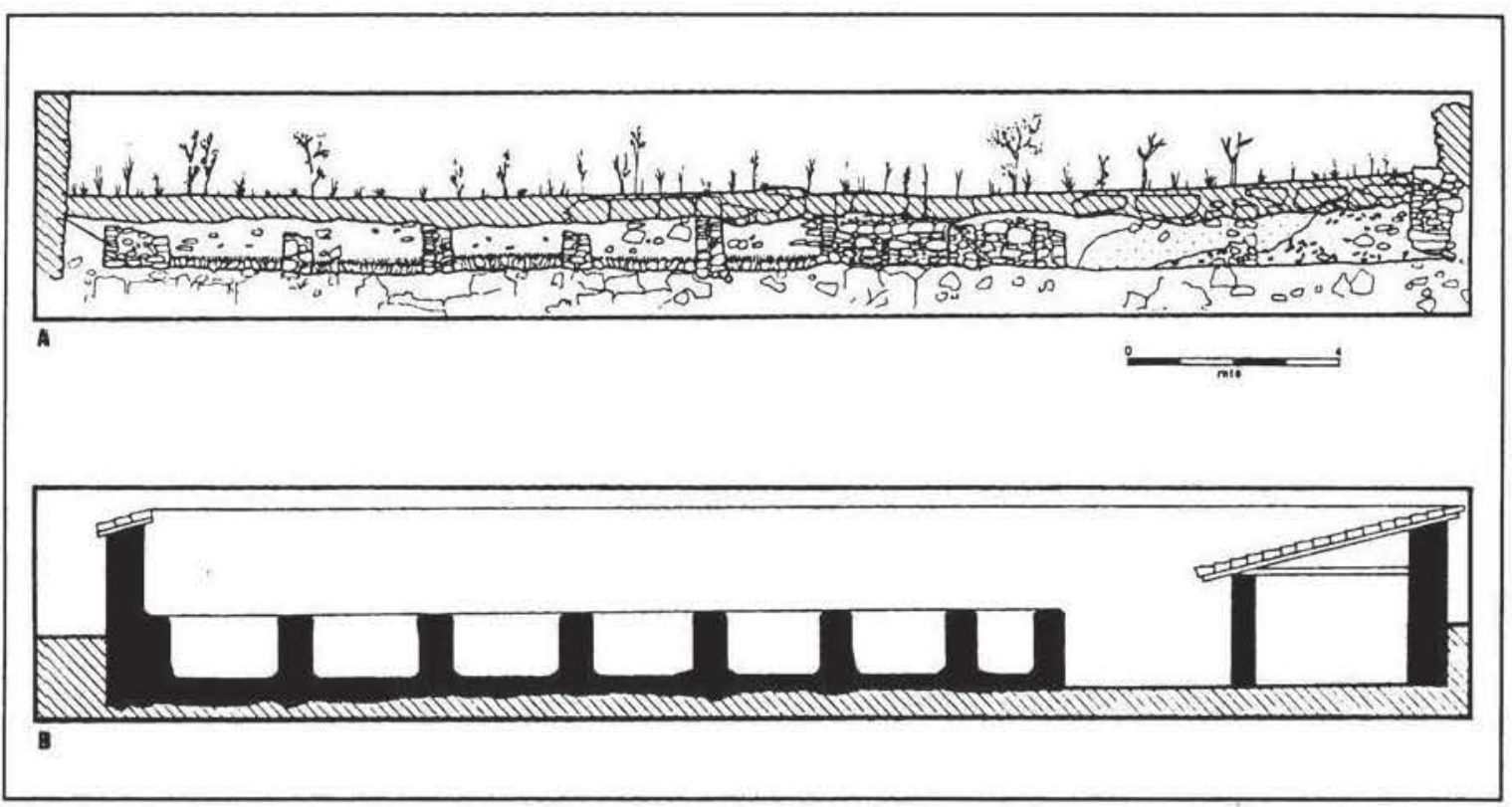

Figura 2.-Instalación salazonera de Cariño, La Coruña (según Naveiro, 1991, 104). 
mente por este autor parece suficientemente contundente como para admitir su inclusión en el censo de núcleos salazoneros.

\section{Espasante (Fig. 1.8)}

Conocido tan sólo a través de las referencias de Maciñeira, en esta localidad fueron localizadas, al menos, diez piletas revestidas con sucesivas capas de opus signinum (Maciñeira, 1947, n.49). Esta obra aparece delimitada por muros de pequeña mamposteria sentada en barro.

No se conoce información más reciente en torno a este yacimiento, si bien, su ubicación coincide con una zona de importantes hallazgos de centros salazoneros (Bares, Area, Cariño) y de salinas explotados en época medieval (Ferreira, 1988, 171). Tales indicios poseen suficiente entidad como para admitir que los hallazgos comentados por F. Maciñeira corresponden a un centro salazonero.

\section{Bares (Fig. 1,9 y 3)}

En la ensenada sita entre este accidente y el cabo de Ortegal, en una escollera cercana, fueron localizados restos de establecimientos probablemente dedicados a la explotación de recursos marinos, quizá salazones (T.I.R., 1991, K-30). Dichos restos quedaron al descubierto, al roturarse, en 1927, la carretera del Puerto de Bares.

El yacimiento, sólo se ha conocido a través de algunas referencias modernas (Maciñeira, 1947, 222 y ss.; López Cuevillas, 1953, 34), siendo nulos los datos actualizados respecto al mismo.
Los trabajos de F.Macineira permitieron poner de relieve la existencia de materiales arqueológicos bastante heterogéneos, ya que se citan fragmentos ude aspecto sigillata» (Maciñeira, 1947. 211), tegulac y capiteles de complicada filiación (Macineira. 1947, 253 y ss.: Bascoy, 1958, 111 y ss.). (iertamente fueron localizadas varias piletas con los angulos interiores redondeados y revocadas mediante opus signinum. que se encontraban delimitadas por toscos muretes de mampuestos trabados con arcilla (Figura 3). Las medidas de estos cetaria eran diferentes si bien parece constatarse 2,40 $\mathrm{m}$. de ancho y una altura conservada de $0,85 \mathrm{~m}$. (Maciñeira, 1947, 223). A estas estructuras se encontraba asociado un conjunto de materiales entre los que destacan ladrillos rectangulares (later?), restos de un ánfora indeterminada y fragmentos de terra sigillata (MACIÑEIRA, 1947, 221 y ss., ns. 45 y 46$)$.

Como dato importante debe indicarse la existencia de un sistema de canalización, realizado mediante piezas de sección rectangular y $50 \mathrm{~cm}$. de largo que ensamblan entre si. Dicha canalización parecia proveer a la factoria de agua, que se captaba de un arroyo situado al O. de la misma (Maciñeira, 1947. figs. pp. 222 y 226 )

Aún al $\mathrm{O}$. de este arroyo y a unos $60 \mathrm{~m}$. de distancia aparecieron nuevos cetaria, también conservando el revestimiento de opus signinum. Una dato interesante, en este grupo, es la existencia de una laja pétrea alargada (15 cm. de grueso), en cuya superficie se había labrado un canalillo finalizado en una "cazoleta» redondeada, a modo de depósito, de unos $25 \mathrm{~cm}$. de diámetro (Maciñeira, 1947, pp. 228 y ss.).
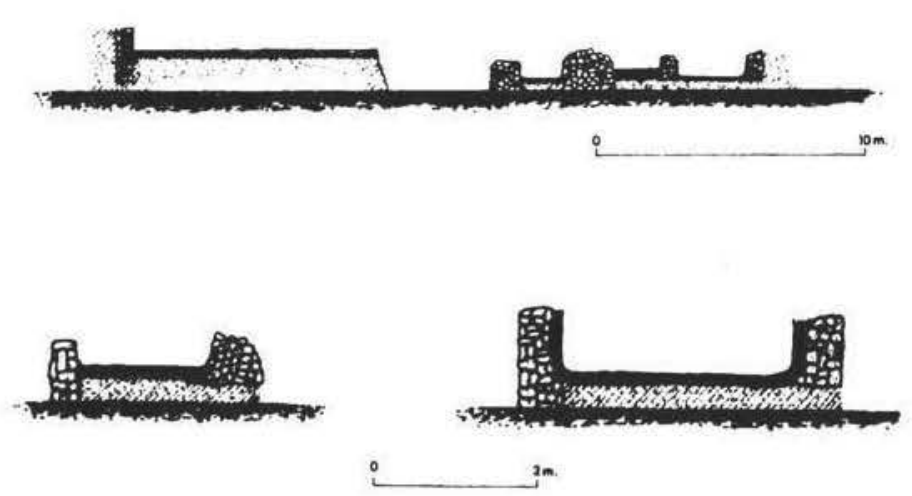

Figura 3.-Piletas de salazón de Bares (dibujo sobre original de Maciñeira, 1947, 224). 


\section{LUGO}

Playa de Area (Vivero) (Fig. 1,10)

A consecuencia de los temporales de 1951 quedaron al descubierto algunos restos romanos en la Playa de Area (Váquez Seijas, 1952, fig. 5) que parecían apuntar a la existencia de una factoria romana de salazones.

El elemento más caracteristico consiste en la presencia de los cetaria o piletas, para cuya impermeabilización se empleó el anteriormente citado opus signinum. Asimismo, se constata la utilización de cuarto de bocel para la unión de las juntas, fenómeno ampliamente observado en los cetaria conocidos. Otros materiales significativos son tegulae, later plano, adobe, ubaldosas» de arcilla, etc. La disposición de los muros conservados toma una orientación perpendicular u oblicua respecto a la playa, si bien ésta pudo presentar distinta disposición en la Antigüedad. Estos muros cubren, a intervalos diversos, un área de aprox. $85 \mathrm{~m}$.

Algunos novedosos trabajos proponen encuadrar este conjunto en el censo de las villae a mare y no en el de los centros salazoneros (Naveiro y Pérez Losada, 1992, n. 12). En nuestra opinión, las caracteristicas del hallazgo parecen suficientemente válidas para admitir su identificación como instalaciones de procesamiento del pescado.

\section{Atribuciones dudosas}

Algunas informaciones apuntan a la existencia de otros núcleos geográficos en los que pudieran haber estado ubicados centros de elaboración del pescado. Sin embargo, ningún dato significativo, de carácter arqueológico, parece corroborar este extremo.

En este caso se encuentra la localidad de Noville (La Coruña), (Fig. 1-D), sobre la que poseiamos escasísima información (Lomba, 1987, 171; Naveiro, 1991, 100, n.86), solventada gracias a los últimos trabajos arqueológicos desarrollados, que apuntan a la existencia exclusiva de una villa tardoimperial (Pérez Losada, 1988). Algo similar ocurre con la villa de Centroña (Pontedeume, La Coruña), (fig. 1-C), en la que a pesar de la presencia de «...sillares, la clave de un arco (...), restos de ánforas, numerosísimos trozos de cerámica sencilla...» (Luengo, 1962,7 y ss.), ningún elemento avala la existencia de industrias de procesamiento del pescado. Otros yacimientos con idéntica problemática son los de Panxón (Fig. 1-A), y Nasos (fig. 1-B), censados como centros salazoneros por algunos investigadores (Lomba, 1987, 175) y, sin embargo, calificados como muy dudosos (Naveiro y Pérez Losada, 1992, n. 12 y fig. 8. p. 81).

Desde el punto de vista histórico, no dejan de ser interesantes las fuentes medievales que avalan la presencia de "pesquerias" en las costas gallegas (Rodriguez Colmenero, 1977, 185 y ns. 96-99). Asi tenemos las menciones a estas instalaciones en la Villa de Calegio en el Miño (935), Melias (844), en las cercanias de una calzada romana, y Oimbra (982) quizá ubicada en el río Támega (Rodríguez Colmenero, 1977, 69). Esta última mención resulta muy significativa, si tenemos en cuenta la importante distancia que separa su ubicación de la desembocadura del Duero (el rio principal) en Oporto y, por tanto, del mar. En este sentido, debemos preguntarnos si estamos ante una factoría orientada a la explotación de fauna dulceacuícola y no marina.

Abundantes son, asimismo, las noticias del medievo en las que se menciona un importante despegue económico de la exportación de conservas de pescado, facilitado por un mayor ritmo de abastecimiento de sal, en el que Galicia, parece una región históricamente deficitaria (Ferreira, 1988, 93 y ss. y $130 \mathrm{y}$ ss.). En general, estos datos no hacen más que avalar la tradición histórica de la explotación industrial de recursos maritimos que siempre han caracterizado las costas gallegas.

\section{ASTURIAS}

Uno de los oficios que contribuyó a consolidar las poblaciones de la costa asturiana durante la Edad Media fue la pesca. Esta actividad, recogida como un derecho en las donaciones de muchas villas altomedievales del Principado, (González Garcia y Ruiz de la Peña, 1972), tuvo un precedente en época romana, según hemos podido documentar en las excavaciones realizadas recientemente en Gijón, cuyos datos se resumen en las líneas siguientes.

\section{Gijón (Figs. 1,11; 4 y 5)}

Al construir un colector de saneamiento delante de la fachada del Palacio de Revillagigedo, junto al puerto de Gijón, se identificaron los restos de un pequeño depósito cuadrangular revestido de opus signinum. Tras una primera documentación de esta estructura, se detuvo la obra para realizar una excavación de urgencia de la máxima extensión posible, con el fin de asociar dicho depósito con otros restos y llegar a definir el contexto arqueológico del hallazgo. 


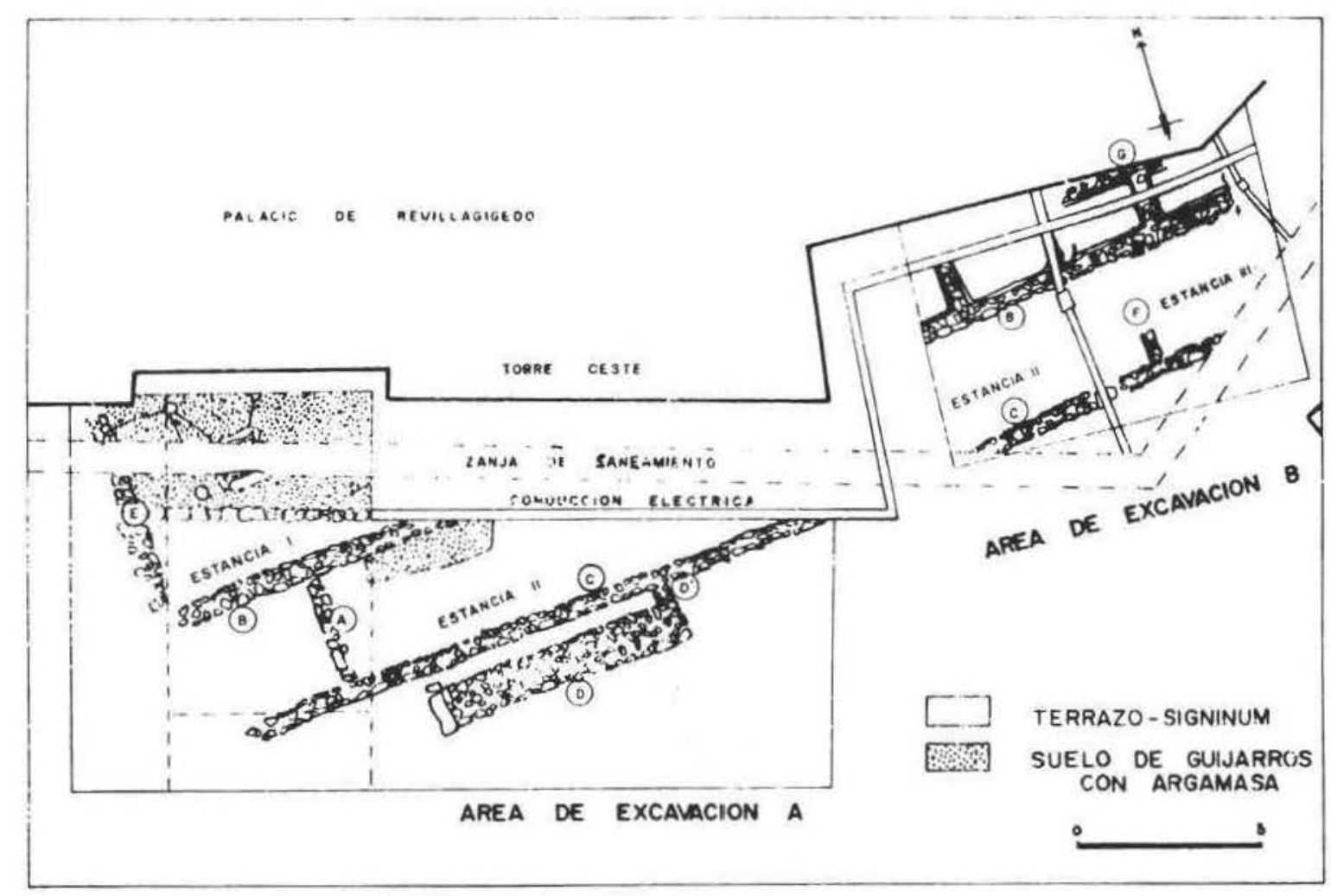

PLANTA GENERAL

Figura 4.-Planta general de la industria de sala/ones de (iijón (Asturias), (según Fdez. Ochoa).

En la parte Noroeste (figura 4. Area A), se documentaron una serie de cimentaciones de muros, algunos con restos del alzado. La composición de los muros era de mampostería de piedras de caliza y arenisca trabadas con argamasa de cal; su anchura oscilaba entre 40 y $60 \mathrm{~cm}$., a excepción del muro D, que media $1,20 \mathrm{~m}$. y que hubo de tener una función especial. Dichos muros configuraban varias estancias de diferentes formas, con suelos también distintos. La estancia I, entre los muros B y C, era cuadrangular y estaba pavimentada con un suelo de guijarros unidos por argamasa. Bajo este nivel de suelo se había construido el depósito n. ${ }^{\circ} 1$ (antes citado), que media $1 \times 1 \mathrm{~m}$. El destrozo causado por la pala mecánica en su fondo nos impidió concretar otros aspectos interesantes como la existencia de algún desagüe o cualquier detalle ilustrativo sobre la funcionalidad de esta estructura o su cronología.

En torno al citado depósito, se hallaron unas pequeñas cazoletas realizadas en el pavimento y revestidas también de opus signinum, que mediante unos canalillos se comunicaban entre si y con el depósito principal. Sobre todo este espacio se habian vertido tégulas e ímbrices fragmentados, prác- ticamente sin materiales asociables a este nivel. Una de las tégulas llevaba el sello (LICINI).

Un muro de gran anchura (muro D) constituía un elemento constructivo peculiar del que se conservaba la zapata. Se levantó siguiendo la inclinación del terreno sin explanación previa apreciable y debió presentar una cara vista en la parte Sur. Fue construido con posterioridad al muro $\mathrm{C}$ y en medio de ambos, en el momento de amortizarse este muro D, se formó un basurero cuyo relleno es uno de los pocos lugares del área excavada que ha proporcionado materiales relativamente abundantes. La funcionalidad de esta estructura, que se levantó separada del muro $C$ intencionadamente, no es fácil de determinar, pues no pudo soportar una gran peso ni desempeñó el papel de contrafuerte.

Con relación a los materiales, las piezas recogidas en el espacio cerrado entre $\mathrm{C}$ y $\mathrm{D}$ pertenecen a ejemplares de $\mathrm{TSH}$ con formas de larga cronologia (Drag.27, 15/17, Hisp.7, Ritt.8, Drag. 37) y otras claramente tardias como la 37 Hispánica. No se haIlaron piezas del horizonte tardoantiguo (TS Africana, Focense, ánforas orientales, etc...) que hemos documentado en otras áreas excavadas de Gijón 


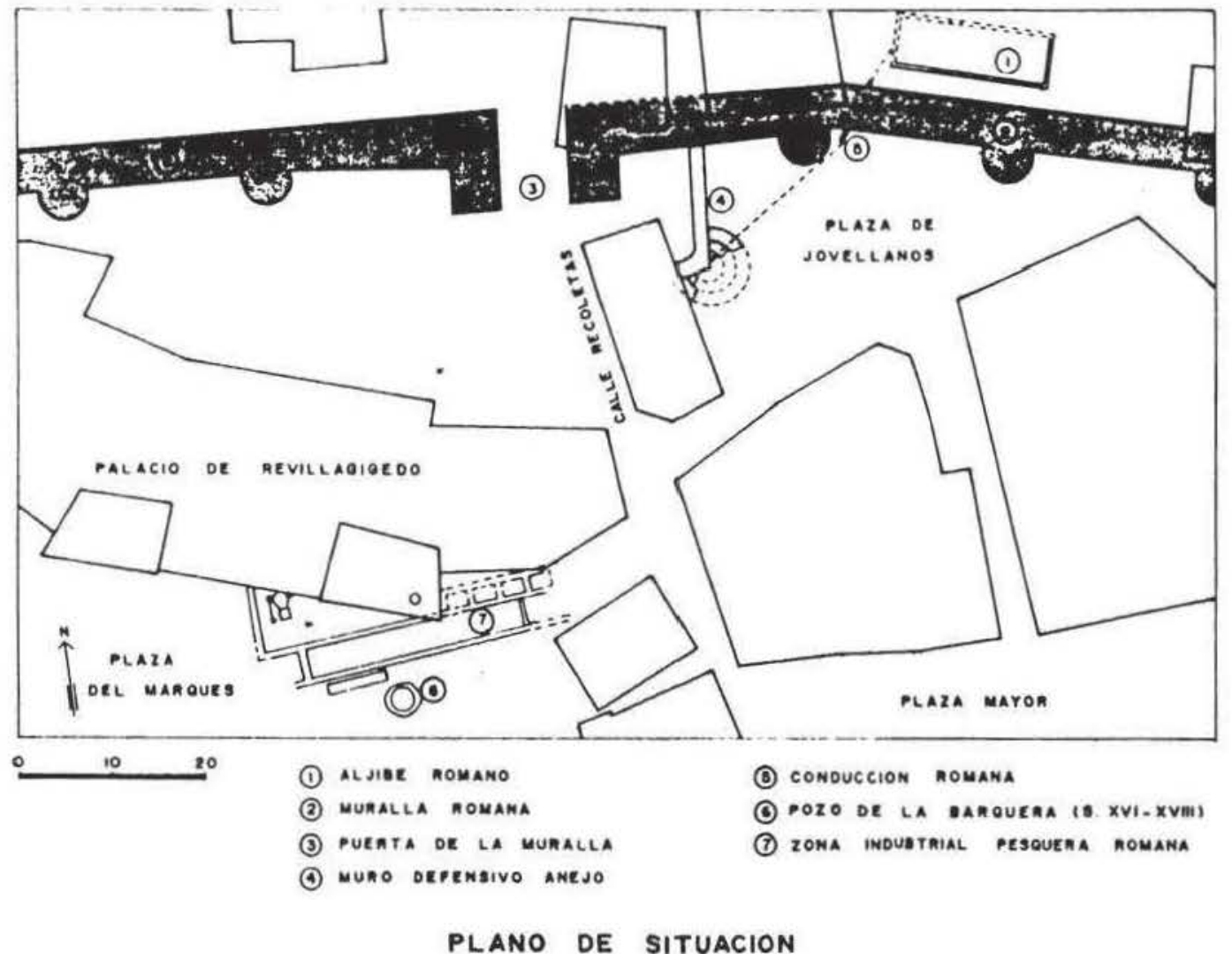

Figura 5.-Plano de situación de la zona. Relación factoria-aljibe (según Fdez. Ochoa).

(Fernández Ochoa et alii, 1992). Entre la cerámica común hay varios mortaria y ollas de borde horizontal inciso; también se recogió una piedra de molino, varios fragmentos de pintura mural muy rodados y algunos metales.

Al Sureste del área que venimos describiendo, se identificó un enorme pozo realizado con sillares de arenisca de $1,40 \mathrm{~m}$. de diámetro. Se trata del llamado "Pozo de la Barquera», conocido por este nombre tanto en la documentación municipal como en el grabado de D. Fernando Valdés de 1630 .

La otra zona excavada, es decir, el espacio Noreste de la Plaza (Figura 4, Area B), se hallaba muy alterado por conducciones modernas. Las zonas fértiles presentaban menor potencia que las del ángulo Noroeste. En la parte Norte de esta zona, se documentaron una serie sucesiva de cuatro piletas rectangulares de $2 \times 1,50 \mathrm{~m}$. Los depósitos estaban constituidos por muros de piedras irregulares trabados con argamasa de cal y revestidos de opus signinum con molduras de cuarto bocel en las esquinas. El arrasamiento de las piletas era casi total y no se hallaron materiales indicativos de su momento de uso o de la fecha de su abandono. A diferencia del depósito $\mathrm{n}^{\circ} 1$, estas piletas no se hallaban bajo el nivel del suelo.

En la zona Oeste, y bajo un potente vertido de tégulas, se configuró una ambiente cuadrangular, la estancia III, con un pavimento de terrazo-signinum, sobre el que se recogieron tres fragmentos informes de TSHT.

Sobre el momento de construcción y uso de estas instalaciones, hemos documentado algún fragmento informe de paredes finas en el estrato inferior de la Estancia II. Podria responder a un momento anterior a la construcción, difícil de precisar, pero siempre posterior al siglo I d.C. Ya hemos indicado que la cronología de las piezas recogidas en los vertidos o basureros oscila entre los siglos it y iv d.C. No hay materiales posteriores a fines del siglo $\mathrm{v}$ d.C.

Parece claro que los restos de la Plaza del Marqués responden a una industria de transformación de recursos marinos, en concreto de salazones, que en algún momento del año, eventualmente también pudo servir para conservar carnes.

La ubicación de este establecimiento en la línea de costa y junto a una de las dos ensenadas que ro- 
dean la peninsula de Santa Catalina, es inmejorable. Hemos comprobado el limite de los restos arqueológicos con el arenal, hecho frecuente en numerosas instalaciones de este tipo. Disponemos de documentos del Archivo Municipal donde se relata el atraque de barcos en esta zona para realizar aguadas. La propia Plaza del Marqués se conocia popularmente como Plaza de la Barquera porque el término "Barquera» se utilizaba en las zonas cantabricas para referirse al embarcadero o lugar de atraque de las barcas (Somoza, 1988, 44, original 1884). Por otro lado, destaca el relativo alejamiento de estas instalaciones del área habitada, lo que era aconsejable para evitar los malos olores producidos por fábricas de este tipo. De hecho, la instalación se sitúa fuera del recinto amurallado (Fernández Ochoa, 1984 y 1992).

Acerca de la importancia de la pesca en el puerto de Gijón y en la costa asturiana, existen datos historiográficos suficientes que la acreditan desde el periodo castreño-romano (Fernández Ochoa, 1982, 7071) y medieval (González Garcia y Ruiz de la Peña. 1972, 76 y ss.) hasta nuestros dias (Bonet, 1970; Muñiz, 1979, 136 y ss.; Fernández Garcia, 1983 , 212-231). Los restos osteológicos hallados en el yacimiento aqui analizado, se han estudiado en el laboratorio de arqueozoología de la UAM. La malacofauna se componia de lapas, ostras, bigaros, mejillones y berberechos recolectados en costa rocosa, a excepción del berberecho. La recogida de moluscos se completaba con especies de pesca litoral bentónica (sama de pluma, breca, maragota) y pelágica (caballa/estornino). Remitimos a la publicación de los resultados donde se discuten y valoran a fondo la presencia y características de todas estas especies en la zona (Morales et alii, 1993).

A los efectos que aquí nos interesan, todas las especies pudieron emplearse para salazones, especialmente los scombridae, y significativamente la caballa/estornino muy apreciada en la elaboración del garum (Marcial, XIII, 102; Estrabón III, 4, 6). No hay vestigios de túnidos o de otros ejemplares más utilizados en las salazones. De cualquier forma, se está demostrando que las industrias salazoneras romanas utilizaban toda clase de peces para confeccionar sus productos (sobre todo algunos productos secundarios como el allex) y no sólo las especies migratorias de gran tamaño (Lepiksaar, 1986; Roselló, 1989; Martinez Maganto, 1993a).

En cuanto al aporte de sal, imprescindible en este tipo de industria, se conoce la existencia de salinas en la costa asturiana desde los siglos $\mathrm{x}$ y $\mathrm{xI}$, situadas entre la desembocadura del río Nalón y Gijón (Gon- zalez (iarcia y Ruiz de la Peña. 1972). La sal se obtendria a partir del agua del mar, puesto que no parece que hubiera minas ni manantiales salinos en la región. Para el caso de Gijón. es bien conocida la referencia de las salinas de la Villa de Ataulio. El 5 de abril del 1078 Maior Froilaz y sus hijos venden al obispo de Oviedo Pedro, la villa de Ataulio, sus officinac salinarum y las pesquerias junto al mar. Estas instalaciones se ubicaban en la zona del actual Natahoyo (Gonzalez (iarcia y Ruiz de la Peña, 1972, 26). No nos parece aventurado proponer la posible obtención de la sal durante el periodo romano en la costa gijonesa.

La disponibilidad de agua dulce, de capital importancia para la limpieza del pescado antes de sazonarlo, creemos que estaba asegurada mediante pozos naturales que son muy abundantes en Cimadevilla (el mismo pozo de La Barquera pudo ser utilizado en época romana), y sobre todo, por un sistema de traida de aguas a partir de un gran aljibe o cisterna descubierto intramuros en la Plaza de Jovellanos. El agua era conducida, a través de la muralla, mediante una canalización con un specus de opus signinum, hasta la factoría (Fernández Ochoa, 1993), (figura 5).

\section{Arribuciones dudosas}

En la costa asturiana, se cita el asentamiento de la ensenada de Bañugues (Gozón), (Fig. 1-E) como lugar relacionable con la explotación de salinas debido, según J. M. González, a la cristalización del topónimo «bañucas» derivado del balneum latino (González, 1976, 11). Aunque esta derivación sea posible, no debemos olvidar que dicho término puede referirse a otros restos antiguos, como termas o baños.

En 1977, J. Bellón realizó unas catas en la parte oriental de la ensenada donde se localizaron restos de muros y otros materiales de época romana. En los fondos del Museo Arqueológico de Oviedo se depositaron los citados materiales que son tegulae, fragmentos lisos de TSH y restos de pinturas murales de tonos ocre y rojo (Fernández Ochoa, 1982, 228). A pesar de estos hallazgos carecemos de información sobre las estructuras descubiertas, pues nunca se publicó la memoria de esta intervención. Rodriguez Asensio, buen conocedor de la zona arqueológica de la ensenada de Bañugues, piensa que los restos alli excavados hace años, muy semejantes a los de Gijón, pudieron pertenecer a un establecimiento industrial pesquero de época romana ( $\mathrm{co}-$ municación verbal). 


\section{( $A N T A B R I A$}

Teniendo en cuenta la ubicación costera y la directriz económica de los núcleos romanos localizados en este tramo del litoral cantábrico, es bastante dificil sostener la ausencia de centros para la elaboración del pescado en la zona cántabra. Sin embargo, recientes excavaciones en esta zona han arrojado resultados negativos en este sentido (Morlote. 1992). Por lo tanto, sólo es posible enumerar algunos datos indirectos y significativos, pero, en modo alguno, suficientemente concluyentes.

La importancia de la industria vinculada a la conservación salina de la carne y del pescado queda puesta de manifiesto por el protagonismo que adquieren las salinas en época medieval. Quizá podamos considerar esta «industria» medieval como un reflejo del interés que los recursos salinos (y su explotación industrial) hubieron de tener en la Antigüedad.

Asi, por ejemplo, con referencia a salinas cántabras. un documento fechado en el 853 comenta (Pérez y Ortiz, 1987, 63) «... y en Cabezón de aquel pozo real todas las semanas del año cada lunes tres pozales de agua moria que se llamaba salada». Asimismo, un documento del año 933 , referido a Cesura, indica: «in illa decania de Cesura tres pocales de moira». No deja de llamar la atención el empleo del término "moira» o "moria», que, indudablemente, debe guardar relación con el término muria ', utilizado en época romana para identificar la base salina en la que se conservaban alimentos (Jardín, 1961, 72 ). Con esta sustancia se confeccionaban las salsas de pescado (garum, allex, liquamen), como podemos deducir en los textos clásicos y medievales (Catón, De Agr., 87; Columella, R. R. XX, 6; Isidoro, Orig. XX, 3, 20; Geopónicas, XX, 46).

A la utilización de las salinas debemos unir las noticias históricas respecto al incremento de núcleos litorales, cuya economía estaba orientada a la pesca y que sufren una clara potenciación en época altomedieval. Este es el caso de Castro Urdiales, Laredo, Santander, San Vicente de la Barquera, etc. (Solana, 1977, 33), asi como la constatación de la pesca de ballena en los puertos cántabros de San Martín de la Arena o Suances (Pérez y Ortiz, 1987, 64 y ss.). La importancia de estos centros portuarios en la Antigüedad no sólo parece constatarse sino que,

\footnotetext{
' Aunque el término "Muria» es un topónimo empleado de forma frecuente, en la zona N. O., para aludir a ruinas antiguas, creemos que los textos medievales presentan una asociación clara del término a pozos y agua salada y no a vestigios antiguos.
}

a juzgar por la dispersión del material numismático especialmente el numerario romano imperial, dichos puertos centralizaron una importante actividad comercial entre el siglo I d.C. y la tardorromanidad (Vega de la Torre, 1982; Pérez E. Illarregui, 1992).

\section{EUSKADI}

Las referencias sobre la pesca durante el Medievo en el Pais Vasco arrancan del siglo $x ı$ en Vizcaya (Garcia de Cortazar et alii,1985, 86-87), y son aún mas tardias para Guipúzcoa (Arizaga, 1978, 58). No se han encontrado restos romanos que sirvieran de precedente de esta actividad en la costa hispana de Euskadi pero si los hallamos en la zona francesa fronteriza.

\section{PAIS VASCO-FRANCÉS}

\section{Guéthary (Laburdi) (Fig. 1,12)}

Una serie de piletas localizadas en 1984 junto a la estación de ferrocarril de Guéthary, fueron consideradas como vestigios de un horno para elaborar aceite de ballena. Tras los estudios de Tobie y Chansac y de M. Esteban, parece claro que se trata de los restos constructivos de una industria de salazón, ubicada en el acantilado sobre el puerto actual.

En 1988, con motivo del hallazgo de una inscripción romana en el mismo lugar, Tobie y Chansac estudiaron estos vestigios y documentaron los restos de dos piletas, aunque se ha podido determinar la existencia de otras seis que formaban un conjunto de ocho. Las dimensiones de estos depósitos eran: $2,62 \mathrm{~m}$. de largo por $2,26 \mathrm{~m}$.de ancho, siendo una de ellas ligeramente más ancha. Se construyeron de mampostería con piedra local unida con mortero; el espesor de los muros era de $30 \mathrm{~cm}$. y la altura de las paredes oscilaba entre 60 y $80 \mathrm{~cm}$. con un máximo de $95 \mathrm{~cm}$. en la parte de unión de los dos depósitos; las piletas conservaban un enlucido de hormigón hidráulico con molduras de cuarto bocel en el fondo y las paredes de cada depósito. No se documentaron indicios de trabazón entre cada pileta ni forma alguna de evacuación (Tobie y Chansac, 1989,90-91). La sal para esta industria procedería de la explotación de sal mineral de los entornos de la región de Bayona (Esteban, 1990a, 177).

Según Tobie y Chansac, los materiales recogidos en el momento de la prospección eran bastante homogéneos y pertenecían a un periodo entre el 15 
y el 50-60 d.C. El conjunto se componía de producciones del taller de Montans, cerámica de paredes finas de Galane, ánforas hispánicas (Pascual 1, Dressel 2-4 y Dressel 7/11) asi como monedas de Augusto y Tiberio. La ausencia de TSH permitia considerar el fin de la ocupación, y en consecuencia de la producción, hacia mediados del siglo I d.C. (Tobie y Chansac, 1989 , n. 2). Según la revisión que realizó M. Esteban de los materiales depositados en el Museo Municipal de Guéthary, se podian contabilizar tambièn fragmentos de TSH decorada con circulos (Esteban, 1990a, 177). Considerando este dato, habria que pensar en una ocupación del espacio más prolongada.

\section{OTROS CENTROS ATLÁNTICOS}

El fenómeno de las industrias para la elaboración del pescado (salazones) en esta zona geográfica, no es en modo alguno un fenómeno extraño. De hecho, su presencia en este sector geográfico no representa más que la continuación, en el litoral atlántico y cantábrico, de una actividad económica ampliamante detectada en una zona tan cercana como es la Lusitania central y meridional (Baltazar, 1983). Ciertamente, los restos hasta ahora conocidos en las provincias cantábricas, no permiten establecer comparaciones (al menos cuantitativamente) respecto a las factorias del Tajo y del Sado (Edmondson, 1987, 100 y ss.). Sin embargo, estos núcleos atlánticos de Lusitania, especialmente activos durante los siglos III y IV d.C., tienen una continuidad geográfica evidente en las industrias, de dimensiones más modestas, situadas en el litoral N. de Hispania. La transición entre la zona central y meridional portuguesa y la zona gallega, se constata en yacimientos como Angeiras o Lama, las factorías más septentrionales de Portugal (Lomba, 1987, 169 y ss.).

Desde Bares a Guethary, las factorias de la fachada cantábrica confirman el desarrollo de estas industrias, que si bien se presentan en la actualidad como puntos casi aislados en una larga costa, parece claro que futuros trabajos añadirán nuevos enclaves.

En este sentido, conviene recordar, siquiera brevemente, las fábricas de salazón de la costa atlántica de la Gallia que marcan, una vez más, la continuidad de las explotaciones pesqueras en los finisterres del Imperio.

No se han documentado restos de factorías al Sur del Loira pero existe una concentración importante de estas industrias más al Norte, en la región armo- ricana, en torno a la bahia de Douarnenez, donde las características geográficas son mucho más favorables. Los sondeos y prospecciones de Sanquer y Galliou en los años 1970-71, dieron como resultado la localización de numerosos restos constructivos de industrias salazoneras. Normalmente ubicadas en playas arenosas, presentan una serie de cetaria paralelos, cuyo número varia entre dos y veinte estructuras de este tipo. A cierta distancia de los enclaves industriales se han localizado otros ambientes interpretados como habitaciones o salas de reunión, debido a los restos de mosaicos y pinturas que decoraban sus paredes (Sanquer y Galliou, 1972).

Las industrias armoricanas se nutrian de la abundante pesca de la zona y, posiblemente, utilizaban la sal que se obtenia mediante calor artificial, siguiendo antiguas tradiciones constatadas en esta región desde la Edad del Bronce (Sanquer y Galliou, 1972, 221). Los materiales arqueológicos (especialmente cerámicas y monedas), indican unas fechas de uso entre los siglos $॥$ y IV d.C.

Por otra parte, la documentación disponible respecto a las costas de Britannia, no es muy abundante. Sin embargo, debe mencionarse la constatación arqueológica de estructuras relacionadas con la elaboración del pescado en torno al Támesis (Bateman y Locker, 1982). Una gran zanja puso al descubierto una serie de atarjeas de madera, que representaban una actividad entre la mitad del siglo 1 d.C. y principios del siglo iv d. C. Estas atarjeas conectaban con un pequeña pileta rectangular de madera, situada cinco metros al E.. Sus características indican que fue construida para contener alguna sustancia de naturaleza posiblemente liquida. El análisis dendrocronológico de los componentes de madera señalan una datación, para dicha estructura, del siglo I d.C. (Milne, 1985, 87).

En conexión con esta estructura fue localizada un ánfora fragmentada en torno a la cual se encontraban numerosos restos de pescado. El análisis de ictiofauna identifica restos de arenque y espadín en cantidades de $84 \%$ y $16 \%$ respectivamente. Algunos fragmentos de Jordanela floridae (sin nombre común en castellano) y lanzones. Este resultado sugiere un origen local para el contenido del ánfora, ya que estas especies, aún hoy día, son típicas en la desembocadura del Támesis (Milne, 1985, 87). Si bien, sólo el espadín, procede de un hábitat claramente dulceacuícola.

Teniendo en cuenta la situación espacial del yacimiento y la conexión existente entre la pileta de madera y los espacios habitacionales, situados sólo $12 \mathrm{~m}$. de distancia, es lógico pensar en unos alma- 
cenes donde las ánforas salarias podrian ser almacenadas (Milne, 1985, 87). En cualquier caso, el hallazgo es suficientemente significativo para aseverar la existencia de centros de elaboración de salazones, si bien no conocemos el número y extensión de los mismos.

Asimismo, parece constatarse el sistema utilizado para el aprovisionamiento de sal. necesario en los procesos de preparado del pescado. Sin duda, la salinas costeras, son especialmente importantes, ya que obtiene la sal marina mediante evaporación natural o, más habitualmente, artificial por calentamiento. Quizá este es el caso el caso de Chidham, en las cercanias de Chichester (Bradley, 1992) o el importante cúmulo de salinas que se agrupan en la desembocadura del propio Támesis y, en general, el litoral de Essex (Jones y Mattingly, 1990, 224, Mapa 6.43). El estudio de estos yacimientos documenta la explotación de estas salinas en época romana, quizá perpetuando una actividad ya iniciada en la Edad del Hierro británica.

Estos datos parece dar aún mayor validez a la documentación medieval disponible, en la que se constata la localización de una factoría de salazones de pescado (arenque) en Durham, curiosamente denominada domus allecaria (Curtis, 1984, 147). Este dato no sólo confirma la continuidad de la producción de salazones en fechas tardías (siglo xIII), sino que, asimismo, atestigua la perduración del término latino Hallex, Allex o Allec ampliamente utilizado en la Antigüedad para denominar una salsa de pescado de calidad secundaria (Martínez Maganto, 1992. 77: C.I.L. $;$ XV-2, 4730, 473I).

\section{ESTUDIO}

Es evidente, que los centros para la elaboración del pescado que hemos enumerado en las páginas anteriores, no constituyen, ni mucho menos, una industria del alcance y la importancia económica de las instalaciones de la Baetica o de la Tingitania. Sin duda, en la mayoria de los casos detectados en las costas del N. O. asistimos a la presencia de pequeños núcleos de producción, caracterizados por una serie de cetaria que parecen apuntar a un abastecimiento local y/o regional (Naveiro, 1991, 105).

En este sentido, cabria preguntarse en qué contexto espacial se enmarcan estos núcleos salazoneros, hecho que, en cierto modo permite definir las posibilidades inmediatas de demanda y el momento cronológico en que se desarrolla la producción. $\mathrm{Pa}$ rece claro que todavía no disponemos de suficiente información como para establecer una clasificación jerárquica de centros, tal y como se ha intentado en alguna ocasión (Lomba, 1987. 167 y ss.).

Pocos son los hallazgos que permiten definir una cronologia altoimperial para estas instalaciones. Un caso interesante es el de Guéthary, en el que el material arqueológico recuperado se encuentra en un horizonte inicial de la primera mitad del siglo i d.C. (Tobie y (hansac, 1989,91). De igual forma, AdroVello parece encuadrarse en un contexto de los siglos I-II d.C., ya que los cetaria descubiertos, situados estratigráficamente bajo los resto de una villa de los siglos III-IV, fueron ocupadas por los nuevos imuros trazados posteriormente (Carro, 1991, 94 y ss.; Naveiro, 1991, 105, n. 103). Quizá los hallazgos de Bares y Espasante puedan, asimismo, situarse dentro de una cronologia altoimperial (Naveiro y Pérez Losada, 1992, 66, n. ${ }^{\circ} 13$ ). Por desgracia, los casos en los que los cetaria parecen asociarse a un castro romanizado, como en Villagarcia y, quizá, en la Playa de la Barra de Hio, no disponemos de una cronología contrastada para los mismos.

La consideración provisional de estos resultados, apunta a una fase cronológica importante para estos centros salazoneros que se sitúa en época altoimperial. En este período, los cetaria se sitúan en las cercanias de los castros litorales, asentamientos ya romanizados. Una segunda fase, más tardia, se caracteriza por la asociación de estos centros a villae, especialmente las villas maritimas (Pérez E. Illarregui, 1992, 7), siendo el recurso económico más importante, aunque no único, de estas unidades productivas. En este segundo caso, la elaboración de las conservas de pescado estaba encaminada a satisfacer el consumo de la propia villa y quizá el de las zonas anexas (Lomba, 1987, 171). Este fenómeno de las villae maritimae cuya orientación económica está relacionada con la pesca y transformación del pescado, ha sido puesta de relieve en otras zonas geográficas tradicionalmente salazoneras, caso de la Baetica (Posac y Rodríguez Oliva, 1979).

Mención aparte merece la factoria de Guéthary, ya que se caracteriza por quedar individualizada como centro exclusivamente salazonero que, si bien se ubica en las cercanias de instalaciones portuarias, no parece depender de centros urbanos de modo claro (Tobie y Chansac, 1989, 92 y ss.). Quizá se trate de una de las factorias más netamente uindustrial» de la zona, en el sentido de la especialización productiva. Algo similar sucede en los casos de Bares y Espasante, pues su relación con algún núcleo de hábitat no está bien concretada, si bien Bares puede guardar relación con el posible centro portuario. Quizá la casuística de estos tres conjuntos indica la co- 
nexión existente entre un centro de producción (factoria) y un centro de comercialización (puerto maritimo). Gijón responderia al mismo esquema, pero en un periodo más tardio, ya que la cronologia de esta factoria no puede ser anterior al siglo II d.C. y su flortuit parece situarse entre los siglos II-IV d.C.

Las características constructivas que presentan estas instalaciones, especialmente las piletas o cetaria. son las mas habituales para el mundo romano. En general, se construyen piletas, delimitadas por pequeños muros de opus incertum (en torno a los 50-60 cm. de espesor), que aseguran el refuerzo horizontal. Por su parte, el suelo del cetarium era el punto de mayor solidez constructiva, como se ha podido determinar en algunas de estas instalaciones. Para el revestimiento interior de los cetaria se emplean sucesivas capas de opus signinum, que se aplican aumentando el grado de fineza de sus componentes, quedando finalmente en la superficie la de mayor finura, hecho que garantiza la necesaria impermeabilización del depósito (Maciñeira, 1947.

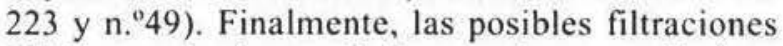
hidricas en las juntas de las paredes eran eliminadas mediante la aplicación de cuarto de bocel que refuerza la unión de las paredes y el suelo de las piletas. Asimismo, este sistema facilitaba la limpieza de los ángulos.

En general, estas piletas se distribuyen de forma ordenada, formando alineamientos que se suceden a intervalos regulares, siendo especialmente significativos los ejemplos de Cariño, Bares y Gijón (figuras 2 a 5). En otros casos, a pesar de los escasos restos conservados, no es difícil comprobar el alineamiento que presentan estas estructuras (Carro, 1991, 94).

Al margen de las propias técnicas constructivas, no es mucho lo que podemos asegurar sobre el ritmo de producción de estos centros. Los cálculos que han establecido algunos autores sobre la producción de estas fábricas son claramente ambiguos, ya que factores relativos como la extensión máxima de la cetaria, la continuidad de su uso (estacional?) y el tiempo de maceración de cada ciclo, son imposibles de determinar (Pascual, 1968, 243 y ss.). Sin embargo, algunos cálculos relativos permiten conocer aproximadamente la capacidad individual de las piletas. Así, en Adro-Vello, las piletas de 1,5 × 1,5 × 1,5 totalizan un volumen de $10,12 \mathrm{~m}^{3} \mathrm{y}$ una producción anual de $184,69 \mathrm{~m}^{3}$, según cálculos del autor basados en ciclos productivos de 20 días (Carro, 1991, 95 ). En el caso de Bares, sólo conocemos la anchura de las paredes $(2,8 \mathrm{~m}$.), pero no la altura total conservada (Maciñeira, 1947, 223), como también sucede en (iijon. hecho que imposibilita cálculos precisos. Esto mismo ocurre en la factoria de Guéthary, pues sólo disponemos de medidas del ancho $(2,26 \mathrm{~m}$.) y del largo $(2,62 \mathrm{~m}$.), faltando la altura total, de la que sólo se conservan $0,8 \mathrm{~m}$. (Tobie y Chansac, 1989, 90). Por tanto, a la luz de estos resultados cualquier conjetura sobre el ritmo de producción resulta aventurada.

Respecto a la funcionalidad de estas piletas, conviene aclarar que no existen indicios que permitan identificarlas como vivaria, es decir, viveros o piscinas naturales a las que tan aficionados eran los romanos (Conta, 1972). Los vivaria requieren unas caracteristicas muy determinadas adaptables a cada tipo de pez y, lo que es más importante, una conexión directa con el mar (Columella, VIII, 17) para permitir, mediante el oleaje, el intercambio natural de agua, cargada de particulas alimenticias y oxigeno. Estas características no han sido detectadas en ninguno de los casos estudiados.

La presencia de tegulae, que numerosos investigadores ponen de relieve en la mayoria de yacimientos salazoneros, parece guardar relación con un pequeño tejado que se colocaba directamente sobre los cetaria con ánimo de proteger la maceración del pescado de la excesiva evaporación (sol directo) o de la desalinización (agua de lluvia), (Ponsich, 1988, 81). Asi, los hallazgos de pilastras que sostiene estos techos y de las propia tegulae en numerosas factorias de la Bética y Tingitania avalan los frecuentes hallazgos de estos mismos materiales en las instalaciones septentrionales de Hispania, siendo muy significativos, en este sentido, los casos de Cariño, Bares (Maciñeira, 1947, 225) o el espectacular vertido de la factoria de Gijón (Fernández Ochoa, 1993). Asimismo, la cubrición de piletas con tegulae se halla bien documentada en los centros galos de la Armórica, donde se han detectado numerosas tegulae completas en el fondo de varios cetaria (Sanquer y Galliou, 1972, 219).

Uno de los aspectos más llamativos respecto a las fábricas de salazón, especialmente en los grandes núcleos industriales de la Bética y de la Tingitania, es la presencia de elementos decorativos (arquitectónicos o pictóricos) asociados a estas industrias. Aunque no parece lógico la existencia de manifestaciones estéticas en instalaciones básicamente funcionales, el hallazgo ocasional de alguno de ellos invita a reconsiderar esta cuestión. De hecho, es bastante habitual encontrar restos de pilastras, columnas, capiteles o basas decoradas, así como estucos pintados o restos marmóreos.

En este caso nuevamente tenemos una coincidencia con algunos hallazgos, asociados a estas in- 
dustrias en las costas septentrionales de Hispania. Asi, por ejemplo, conviene citar los capiteles de Bares, localizados por Maciñeira (1947, 235 y ss.), que podrían corresponderse, no sin dificultades, con los hallazgos de capiteles jónicos en la factoría de Jảvea (Martin, 1970, 144, Láms. V y VI), el capitel de mármol rosáceo, inacabado de la factoria onubense de la (alle Palos (Delamo, 1976, 38, Fig. 7) o los toscos capiteles de Belo (Ponsich, 1976, 78). Elementos semejantes son las basas de columna, bien labradas de Cotta (Ponsich y Tarradell, 1965, fig. 43) o de Lixus (Ponsich y Tarradell, 1965, 26, fig. 15).

El caso del estuco pintado no es menos significativo; a titulo de ejemplo, los restos de este tipo identificados en la factoria de Area (Vázquez. Seijas, 1952, 111 y Fig. 4), Adro Vello (Carro, 1991, 95) o en Gijón, podrán tener paralelos en los fragmentos de estuco pintado de la Calle Palos (Delamo 1976, 38), de Tahadart (Ponsich y Tarradell, 1965, 48 ) o de Almuñécar (Sotomayor, 1971, 155). Estos datos, aunque parcos y, a veces, poco contextualizados, pudieran indicar que la presencia de elementos decorativos no debe relacionarse, exclusivamente, con una villa o asentamiento similar, sino que, en numerosas ocasiones, puede aparecer en conexión con centros salazoneros, como sucede en la Armórica francesa (Sanquer y Galliou, 1972). Sin embargo, quizá la hipótesis más probable se encuentre en una vía intermedia: bien por un cambio en la orientación del hábitat en el que estructuras de villa quedan subsumidas por la construcción de cetaria, como parece detectarse en la villa andaluza de Sabinillas (Posac y Rodríguez Oliva, 1979); o bien por la existencia de las propias villae maritimae, que cuentan, asimismo, con piletas para la maceración de recursos marítimos, siendo, por tanto, núcleos en los que se conjugan los elementos estéticos (pinturas, mosaicos) y funcionales (cetaria).

En el caso de esta especializada actividad, como en tantos otros casos, se comprueba la existencia de una fuerte tradición en las técnicas pesqueras que se mantiene, sin grandes modificaciones, hasta principios de este siglo. Sistemas de captura similares a los tradicionalmente empleados en este litoral, debieron abastecer a las fábricas de salazón en la Antigüedad (Martínez Maganto, 1993b). Algunos datos modernos no dejan de resultar atrayentes, así la cuerda de pesca armada con varios anzuelos es llamada linia en Asturias (Barriuso, 1992, 12), mientras que el latín clásico utilizaba el vocablo linea para denominar al sedal armado para la pesca (Lafaye, 1969, 489). Existen además otras grandes afinidades entre los aparejos y técnicas actuales (Merino, 1990;
Barriuso, 1992) y los utilizados en la Antigüedad (Martinez Maganto, 1993b) e incluso técnicas pesqueras similares ya utilizadas por los habitantes de los castros litorales en todo este sector costero (Pereira, 1983, 154 y ss.; Vázquez Varela, 1979). Entre dichas técnicas destaca la de los «corrales de pesca», sistema que no sólo conocemos a través de documentos medievales en las costas gallegas ( Ferreira, 1988, 132), sino que, asimismo, se han detectado en el litoral gaditano, presumiblemente asociados a industrias salazoneras locales (Moreno y Abad, 1971).

Sin embargo, a pesar de la constatación de estas técnicas pesqueras, no es frecuente hallar restos de fauna marina o dulceacuícola en estos yacimientos, siendo, tal carencia, uno de los argumentos más utilizados para negar la vinculación entre estas industrias y el procesamiento del pescado. Sin duda, es un hecho extraño si consideramos que el pescado era la «materia prima» para la elaboración de salsamenta y salsas. Sin embargo, como ya hemos defendido en otro lugar (Martínez Maganto, 1992, 79) esta ausencia se debe a que el pescado era aprovechado de forma integral. Esto es: la carne se salaba (salsamenta), la sangre, visceras y otros componentes eran utilizados para la confección de salsas de primera calidad (Marcial, XIII, 102; Geopónicas, XX, 46), asi como para cebo (Eliano; $\mathrm{XIV}, 22$ ). Finalmente, los componentes esqueléticos podían ser triturados, una vez secos, para obtener la "harina de pescado» (Eliano, XVII, 31) producto con numerosas aplicaciones (abono, alimentación animal, etc.). En este sentido, resulta curiosa la presencia, en diversos yacimientos, de utensilios relacionados con labores de molienda, caso de los molinos manuales localizados en Bares (Maciñeira 1947, 231, Lám XXIII B) y Gijón (Fernández Ochoa, 1993) o los morteros de este mismo yacimiento.

De cualquier forma, la ausencia sistemática de ictiofauna, queda definitivamente superada gracias a los hallazgos de Gijón (Fernández Ochoa, 1993) y, especialmente, Adro-Vello (Carro, 1991, 95), lugares en los que se identifican restos faunísticos, con taxones como sardina, caballa, jurel, etc. Además, la riqueza piscícola de esta zona queda fuera de toda duda, pues, ya desde la Antigüedad, tenemos noticias en torno a ella (Marcial X, 37). Aún a finales del siglo xviI, Cornide menciona las técnicas del salado del pescado en las costas gallegas, así como las especies de pescado que podian orientarse a este procesamiento. Entre ellas destaca la merluza, rodaballo, caballa, sarda, atún jurel, sardina, anchoa, abadejo, etc., especies que, en no 
pocas ocasiones, logramos documentar en industrias de salazón o en el interior de envases anfóricos salarios (Lepiksaar, 1986: Morales y Roselló, 1989).

En la zona que nos ocupa la recuperación de materiales arqueológicos relacionados con la pesca no permite definir de forma segura su implicación en la captura masiva de pescado, habituales en las industrias de salazón. Sin embargo, debemos considerar la gran tradición castreña en el ámbito de la pesca (Vázquez Varela, 1979) a juzgar por la presencia de anzuelos y pesas de red recuperados en los castros asturianos y otros yacimiento terrestres y submarinos (Maya, 1983a, 36: Benito, 1988. 157).

Al margen de la importancia que especies marinas de talla menor hubieron de tener en la tradicional pesca del N.O. en la Antigüedad, hemos de considerar la posibilidad de la explotación de la ballena como una importante fuente de recursos para las industrias de elaboración.

Numerosos detalles respecto a la captura de estos mamiferos en la Antigüedad quedan recogidos por Opiano (Halieutica, V, 115 y ss.). Por otra parte, algunos textos medievales y modernos destacan la importancia de la pesca de la ballena en las costas septentrionales (Lence, 1950; González y Ruiz de la Peña, 1972; Garcia de Cortazar et alii, 1985; Ferreira, 1988, 137), lugares en los que la presencia de estos animales hubo de ser realmente importante (Plinio; IX, 3). No en vano algunos puertos pesqueros en épocas más avanzadas parecian especializados en la captura de estos animales (Vázquez Seijas, 1952, 112; Pérez y Ortiz, 1987, 64 y ss.) cuya presencia se constata, asimismo, en aguas mediterráneas (Plinio; IX, 12; Estrabón III, 2, 7), donde también fue capturada y sometida a procesamiento industrial (Ponsich, 1988, 39). Por tanto, la pesca de la ballena responde a una tradición que arranca en la Antigüedad y se ve continuada en distintos lugares, especialmente en zonas donde la presencia de estos mamíferos suele ser habitual. Los beneficios obtenidos con dicha actividad eran realmente importantes ya que la ballena es un animal con enormes y variadas posibilidades de explotación (aceite refinado, carne, grasa, huesos...).

Quizá en este sentido, haya que interpretar la presencia de huesos de ballena asociados a restos de industrias salazoneras, si bien la coetaneidad contextual de los mismos no está bien definida. Algunos casos dignos de mención son los hallazgos de Bares (Maciñeira, 1947, 228, n. 56), Gijón (Morales, 1993, e.p.), o las menciones de Maciñeira sobre su probable empleo, para el mortero utilizado en Bares: «..quizá hecho con algún liquido oleoso como aglutinanten (Maciñeira. 1947, 233).

Un hallazgo que pudiera ponerse en relación con la captura de cetáceos, es el que hemos llamado "cazoletas con canalillos", conocidas a través de los trabajos sobre Bares (Maciñeira. 1947, 228-229) y Gijón (Fernández Ochoa, 1993). asi como, probablemente, sobre Oimbra (Rodriguez Colmenero, 1977. 321). Este último hallazgo es el más curioso si tenemos en cuenta, como ya se ha mencionado, que Oimbra es una localidad interior, cuyas posibles pesquerias debian orientarse a la captura de especies fluviales.

Las caracteristicas y disposición de estas estructuras invita a pensar en algún proceso de "destilación" dificilmente identificable. No es improbable que la obtención de aceite refinado de ballena fuera una de sus posibles explicaciones, aunque, teniendo en cuenta la parquedad de datos disponibles y lo inusual del hallazgo, es una conclusión prematura. Sin embargo, el que estos restos pudieran interpretarse como colectores de agua de lluvia (al modo de impluvia), quizá para favorecer puntos de aguada en el tránsito naval, no parece probable. De hecho, los datos recogidos tanto en Gijón como en Bares, invalidan dicha hipótesis. En el primer caso, en las cercanias de estas "cazoletas" se ubica un pozo de agua dulce, además del aljibe intramuros; en el segundo caso, la presencia, al $\mathrm{O}$. de los cetaria, de un arroyo con su propia canalización haria innecesaria una obra de esta envergadura sólo para el acúmulo de agua dulce. Por tanto, habrá que buscar otra explicación más verosimil a este fenómeno.

En cuanto al abastecimiento de sal, imprescindible en un proceso de este tipo, son los documentos medievales los que aportan una mayor información sobre la existencia de yacimientos salinos. Dichos yacimientos son especialmente importantes en la margen meridional de la ría de Arosa, en cuyas cercanías se ubican los centros ya mencionados de Villagarcia y Adro Vello - O Grove, hecho sin lugar a dudas sintomático que conviene tener presente (Barreiro, 1988, 246). En este sentido, debemos recordar la posible estructura localizada en Angeiras, que pretende ponerse en relación con una salina (Naveiro, 1991, ns. 88 y 98).

Algunos topónimos gallegos actuales, como Salnés, Punta de la Sal, Salga, etc... (Ảlvarez Limeses, 1936,424 y 489), pueden ser bastante reveladores como indicio de la explotación de la sal en fases históricas anteriores (Alvarez Limeses, 1936, 415; Ferreira, 1988, 156 y ss.). Asimismo, las mansiones de la discutida Via XVIII, Salaniana y Salientibus 
(Itin.Ant. 427,6 y 428,4: Ravennate, IV, 45) ₹. podrian hacer referencia a la presencia de salinas minerales (sal gema o similares) susceptibles de explotación en la Antigüedad (Mangas y Hernando. 1990/91, 223 y ss.). En la zona asturiana, tenemos bien documentada la explotación de salinas medievales en los concejos de Gozón y en la costa gijonesa (González Garcia y Ruiz de la Peña, 1972). Finalmente, en la costa Este cantábrica asistimos a un fenómeno similar, ya que en las cercanias de Guéthary persiste el topónimo Salies (Esteban, 1990a, 177).

Asi pues, la existencia de numerosos topónimos relativos a la sal, tanto de origen romano como medieval, en todo el arco N.O. parece matizar o, incluso desmentir, el texto de Estrabón en el que se alude a la demanda de sal en estas regiones (Estrabón; III, 5,11 ), texto, por otra parte, referido a las inciertas Kassitérides. Sin embargo, este mismo autor (III, 3, 7) menciona la existencia de sal en la zona montañosa septentrional, señalando que: «..es purpúrea, pero se hace blanca al molerla». Esta caracteristica, desde la óptica geológica, parece propia de la zona oriental de los Picos de Europa, hecho que bien pudiera avalar el protagonismo de centros salineros locales, caso de Cabezón de la Sal, puesto ya de relieve por García y Bellido (1986, 123, n.195). Además, la existencia de estos centros salineros queda, asimismo, corroborada por la documentación medieval, que alude a la existencia de pozos naturales de agua salada (Mangas y Hernando, 1990/91, 223). Conviene recordar, que numerosos centros salazoneros de esta costa, estaban ubicados en lugares que los documentos tardomedievales censan como salinas y alfolíes en explotación, entre ellos Villagarcía, Vivero, Espasante, etc... (Ferreira, 1988, 171).

A pesar de la ausencia de prospecciones y excavaciones extensivas, que permitan conocer la entidad de los yacimientos, algunos autores sostienen que nos encontramos ante "fábricas de tipo medio» (Lomba, 1987, 168). Se trata, sin duda, de aseveraciones poco afortunadas, ya que, por el momento, sólo disponemos de elementos de juicio tan precarios que no conviene generalizar nuestras hipótesis en cuanto a una jerarquía de centros.

Respecto a la escasa presencia de material anfórico asociado a estos centros, debemos considerar que en una fase inicial las salazones, suponen una pequeña parte de las importaciones en la zona

2. Dejando al margen la misma mención en la tabla 4 del polémico Itinerario de barro. septentrional de Hispania (posiblemente inferior a un $10 \%$ del total), si bien no deja de ser significativa la presencia de ánforas salarias en el litoral atlántico-cantábrico (MAS, 1976, 250) bien sea en Asturias (Maya, 1983b, 240; 1987/8, 31 y ss.; Fernández, 1982, 116 y ss., 124), Cantabria (Garcia y Bellido González, 1949, 242 y ss.), Euskadi (Mezquiriz 1964; Martin Bueno et alii, 1982, 37) o, muy especialmente, en Galicia (Naveiro, 1981 y 1982: Diaz Álvarez, 1984), donde se constata su presencia conjunta en algunos yacimientos, asi como en los posibles pecios. Este hecho implica una demanda de productos derivados de las salazones, de cierta importancia, especialmente en torno al cambio de era, aunque en retroceso constante durante los dos siglos sucesivos.

Asi pues, la escasa presencia de material anfórico salario, principalmente durante los siglos ॥-III d.C., puede guardar relación con la existencia de pequeños centros de fabricación de estos mismos productos extendidos por todo el litoral septentrional. Posiblemente, otros centros satisfacian el mercado regional desbancando de forma progresiva la demanda de los productos originarios béticos, de mayor precio.

\section{VALORACIÓN FINAL}

En el estado actual de la investigación, una primera conclusión apunta hacia la necesidad de completar el vacio espacial que existe en el mapa de dispersión de factorias en la Hispania Romana. La constatación de centros dedicados a la elaboración del pescado en el N. y N.O. de la Península Ibérica queda corroborada a través de los datos arqueológi$\cos$, que hemos ido concretando en las páginas anteriores. Resulta sorprendente, dada la antigüedad de algunas publicaciones, que un hecho de estas caracteristicas haya sido relegado en muchas de las publicaciones acerca de la romanización de la zona hasta fecha reciente.

La densidad de los hallazgos de estas industrias parece ser más elevado en la fachada atlántica de las Rias Bajas gallegas, que en el Cantábrico. Las condiciones más favorables de esta costa podrían justificar este hecho; sin embargo, conviene llamar la atención acerca de los desiguales niveles de investigación arqueológica en una zona y en otra. El avance de las excavaciones en las costas de Cantabria y Euskadi podria modificar el futuro panorama, como ha sucedido en el N. de Galicia y Asturias, con descubrimientos tan significativos como Cariño y Gijón. 
Como ya hemos indicado en nuestro estudio, no estamos en condiciones de establecer una clasificación jerárquica de los centros productivos. Tan sólo podemos apuntar que se encuentran en relación con diversos núcleos costeros (castro romanizado, $v i$ llae o enclaves portuarios). Su producción bien pudiera estar orientada al abastecimiento de un mercado local o regional. durante todo el periodo romano. La implantación de estas industrias acontece en época altoimperial, aunque se prolonga e incrementa en fases tardias, especialmente en los siglos ॥ y $\mathrm{W}$ d.C.

En cuanto a los restos conservados, cabe anotar que responden a un sistema constructivo común (cetaria, muros de mamposteria, opus signinum, etc.) acuñado en las industrias bien conocidas del área mediterránea.

Por último, los análisis de ictiofauna permiten identificar una enorme riqueza piscicola que sería empleada en estas factorias. La sal no debió constituir un problema, ya que la documentación medieval de la zona avala la obtención de tan preciado producto mediante la explotación de salinas o el desecado artificial. Por tanto, estas industrias potencian el dinamismo económico en actividades paralelas, como la pesca o las salinas, si bien no es posible determinar la intensidad de esta producción.

La enorme tradición pesquera y conservera en la región N. y N.O. de España, a lo largo de la historia, encuentra sus referencias más antiguas en estas modestas instalaciones que, a su vez, son indicio evidente de la adopción de gustos alimenticios típicamente romanos.

\section{REFERENCIAS BIBLIOGRÁFICAS}

Acuña Castroniejo, F. (1980) «Vigo en la Antigüedad», en Cunqueiro, A. Y. Álvarf., J, M. ${ }^{\text {a: }}$ Vigo en su historia. Vigo.

Álvarez Limeses, G. (1936): Volumen dedicado a la "Provincia de Pontevedra», en CARreras, F.: Geografia General del Reino de Galicia. Barcelona.

Alvargonzález, C. (1965): Termas romanas de Campo Valdés. Gijón.

ARIZAGA, B. (1978): El nacimiento de las villas guipuzcoanas en los siglos xIII y XIV. Morfologia $y$ funciones urbanas. San Sebastián.

BALtAZAR, L. F. (1983): «Indústrias romana de salga em Portugal» Al-madam, 1; Almada.

BARREIRo, J. (1988): "As rias Baixas galegas nos séculos IX-XIII: Economía e sociedade». Coloquio de Etnogrufia Maritima (Museo Pobo Galegol Xunta de Galicia).
BARril so, E. (1992): Artes de pesca tradicionales en Asturias. Candas.

Bascos, R. (1958): La comarcu del Ortegal en el II Milenio antes de Jesucristo. Ortigueira.

BATfMAN, N. Y. Lo(kiR, A. (1982): "The sauce of the Thames". London Archaeologist, 4. London.

BFNITo. A. M. (1988): "Cerámicas del yacimiento submarino del Cabo de Higuer (Hondarribia)". Munihe, 40. San Sebastián.

Binolt, F. (1959): "L'économie de littoral de la Narbonnaise à l'époque antique: le commerce du sel et les pêcheries" R. St. Liguri, 25. Bordighera.

Bi:rthi:ot, A. (1933): "La Côte océanique de gaule d'après Ptoléméen. R. Et. Anciennes, 35. Paris.

Bı Azouf\%, A. (1894): "Las costas de España en la época romana”. Bol. Real Acad. Historia, 24/25. Madrid.

Bonit, J. A. (1970): Biografia de la villa y puerto de Gijón. Gijón.

BouzA BRIY, F. (1957): «O castro da Albore e os contactos antre a Bretaña e a Galiza na época romana». Homaxe a F. López Cuevillas. Santiago de Compostela.

Bouza, F. Alvare\%, J. M. a., y Masso, E. (1971): «Las aras del santuario galaico-romano de Donón (HioCangas)". Cuad. Est. Gallegos, 17-51. Santiago de Compostela.

BRADLEY, R. (1992): «Roman salt production in Chichester Harbour: Rescue excavations at Chidham, West Sussex». Britannia, 23. London.

CARro, X. (1987): "Xacemento antropo-arqueoloxico de Adro-Vello (San Vicezo de O Grove, Pontevedra)». Arqueoloxia. Informes, 1. La Coruña.

Carro, X. (1991): «Adro Vello (S. Vicenzo do Grove, Pontevedra)". Arqueoloxia. Informes, 2. La Coruña.

ContA, G. D. (1972): «Note sulle pescherie maritime nel mondo romano", en SCHмiEDT, G.: Il livello Antico del Mar Tirreno. Testimonianze dei resti archaeologici. Firenze.

CUNLIFFE, B. (1984):»Relations between Britain and Gaul in the First Century B.C. and early First Century A.D.m, en Macready, S., y Thompson, F. H.(Eds.): Cross-Channel trade between Gaul and Britain in the Pre-Roman Iron Age. London.

Curtis, R. I. (1984): «Negotiatores Allecarii and the Herring». Phoenix, 38-2. Toronto.

Curtis, R. I. (1991): Garum and Salsamenta. Production and commerce in materia medica. Leiden.

DE LA PENA, A. (1984): «Primeras prospecciones arqueológicas subacuáticas en el litoral de la pro- 
vincia de Pontevedran. Pontevedra Arqueologic $a$. 1. Pontevedra.

DiA/ Alvart/, P. (1984): Anforas romanas en el eje galaico-lusitano. Vigo.

DoN, R. ( 1954): "Itineraires maritimes occidentaux dans l'Antiquitè». Bull. Assoc: des Géographes Françaises, 243-244. Paris.

Emmondoson, J. C. (1987): Two industries in Roman Lusitania. Mining and Garum Production (B.A.R. Int.Ser., 362). Oxford.

EdMondoson, J. C. (1990): «Le garum en Lusitanie urbaine et rurale: Hiérarchies de demande et production». En Les Villes de Lusitanie Romaine. Paris.

Esteban, M. (1990a): El País Vasco atlántico en época romana. Mundaiz, 6. San Sebastián.

Esteban, M. (1990b): «Aproximación a la Guipúzcoa de los primeros siglos de nuestra Era». Munibe 42. San Sebastián.

Fariña, F; DI: LA Peña, A., y Sierra, J. C. (1975): "Restos de una villa romana en Hío". Museo de Pontevedra, 29. Pontevedra.

Fernandez Garcia, F. (1983): "La pesca maritima en Asturias», En Geografia de Asturias, Vol. III, Salinas.

Fernandez Ochoa, C. (1982): Asturias en época romana. Madrid.

FERnÁndez OChOA, C. (1992): «Excavaciones en la muralla romana de Cimadevilla de Gijón (198789 )", en Excavaciones Arqueológicas en Asturias 1987-90. Oviedo.

Fernandez Ochoa, C. (1993): «Gijón romano y su contacto con el mar: restos de una industria de salazones de época romana». Actas de las III Jornadas de Arqueologia Subacuática en Asturias. Oviedo (e.p.).

Fernandez OchoA, C. et alii (1992): «Gijón en el periodo tardoantiguo: las cerámicas importadas de las excavaciones de Cimadevilla». A.Esp.A., 65. Madrid.

FERnÁNDEZ OCHOA, C. et alii (1984): «Excavaciones en la muralla de Cimadevilla», en Gijón Romano. Madrid.

Ferreira, E. (1988): Galicia en el comercio maritimo medieval. La Coruña.

FLOR, G. (1991): "El litoral asturiano». Jornadas de Arqueologia Subacuática en Asturias. Oviedo.

García y Bellido, A. (1986): España y los españoles hace dos mil años. Según la Geografia de Strábon. Madrid.

García y Bellido, A., y González Echegaray, J. (1949): «Tres piezas del museo arqueológico provincial de Santander». A. Esp. A., 22. Madrid.
Garcia 1H: Corta/Ar, J. A. él alii (1985): Bizcaya en la Edad Media. San Sebastián.

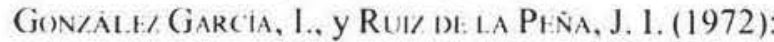
"La economia salinera en la Asturias medieval», Asturiense Medievalia. 1. Oviedo.

IGiL:SıAS, J. M., y MuǸI\%, J. A. (1992): Las comunicaciones en la Cantahria romana. Santander.

IMMER/FEL. M. (1990): «Profession: negotiator allecarius. Fabrication et commerce de sauce de poissons dans le Nord-Ouest de l'Empire Romain». Oudheid Kundige Mede Belingen, 70. Leiden.

JarDiN, C. (1961): "Garum et sauces de poisson de l'antiquité» R. St. Liguri, 17; 70-96, Bordighera.

Jiménez Contreras, S. (1986): "La industria del pescado en la Antigüedad», Rev. de Arqueología, 68. Madrid.

Jones, B., y Mattingly, D. (1990): An Atlas of Roman Britain. Somerset.

LAFAYE, G. (1969): «Piscatio» (Vol.IV/1, p. 489-494), en Daremberg,CH., y Sagilio, E.: Dict. des Antiquités Grècques et Romaines. IV/2; Graz.

LFincE-SANTAR, E. (1950): "La pesca de ballenas en la costa de la antigua provincia de Mondoñedow. Bol. Comisión de Monumentos de Lugo, 4-33. Lugo.

LePIKSAAR, J. (1986): «Tierreste in einer römische amphore aus Salzburg (Mozartplatz 4)». Bayerische Vorgeschichts-Blätter, 51. München.

LomBA, A. M. (1987): "Contribución al estudio de la industria de salazón de época romana en el N.O. peninsular». Lucerna (Ser. II), 2.

López Cuevillas, F. (1953): "La Oestrimnida y sus relaciones maritimas». Cuad. Est. Gallegos, 8. Santiago de Compostela.

Luengo, J. M. ${ }^{a}$. (1962): «Las excavaciones de la villa romana de Centroña, Puentedeume (La Coruña)». Cuadernos de Estudios Gallegos, 17-51. Santiago de Compostela.

Maciñeira, F. (1933): «El Ortegal en el culto de los cabos». Bol.R.Acad.Gallega, 249. La Coruña.

MacıÑeıra, F. (1947): Bares. Puerto hispánico de la primitiva navegación occidental. Santiago de Compostela.

Mangas, J., y Hernando, M. ${ }^{a}$ R. (1990/91): "La sal y las relaciones intercomunitarias en la Península Ibérica durante la antigüedad». Memorias de $H^{a}$ Antigua, 11/12, Oviedo.

Martín Bueno, M. et alii (1982): «La arqueología subacuática en las costas del N. y N.O. Peninsular». VI Congr. Int. Arq. Subacuática. Cartagena.

MARTIN-KILCHER, S. (1990): «Fischsaucen und fischkonserven aus dem römische Gallien». Archäologie der Schweiz, 13-1. Liestal. 
MARTINi: MAgiAnto, J. (1992): «Las salazones romanas: Aportes historiográficos de interés en Arqueozoologia». Archaeofauna, 1. Madrid.

Martintz. Magianto, J. (1993a): El Yacimiento suhmarino de "Pecio Gandolfo". Producción y comercializacion naval de salazones béticas en época altoimperial romana. (Memoria de Licenciatura inédita. Univ. Autónoma de Madrid).

Martinez. Maganto, J. (1993b): «Las técnicas de pesca en la antigüedad y su implicación económica en el abastecimiento de las industrias de salazón». Cuad. Prehist. y. Arq. de la U.A.M. (e.p.). Madrid.

Mis, J. (1976): «Relaciones comerciales entre ciudades augusteas a través de las ánforas imperiales hispánicas». I Symp. Ciudades augusteas. Vol.II. Zaragoza.

MAYA, J. L. (1983a): "La cultura castreña asturiana». Indigenismo y romanización en el Conventus Asturum. Oviedo.

MAYA, J. L. (1983b): "La cultura castreña asturiana. Su etapa Romano-provincial», Lancia, 1 (Cántabros y Astures). León.

MaYA, J. L. (1987/8): La cultura material de los Castros Asturianos (Estudios Antigüedad, 4-5). Barcelona.

MERINo, J. M. (1990): «Sobre algunas técnicas pesqueras tradicionales vascas». Munibe, 42, San Sebastián.

Mezquiriz, M. A A. (1964): «Notas sobre arqueología submarina en el Cantábrico». Munibe, 16, San Sebastián.

MILlán, I. (1978): Sobre las aras del santuario de Donón (Hio, Pontevedra) supuestamente dedicadas a Liber. (Publicaciones del Museo Quiñones de León $\mathrm{n}^{\circ}{ }^{\circ}$ ). Vigo.

MILNE, G. (Ed.) (1985): The Port of Roman London. London.

Morales, A. (e.p.): "Whale remains in a Northern spanish roman site?" (manuscrito inédito).

Morales, A., y Roselló, E. (1989): «Informe sobre la fauna ictiológica recuperada en un àmfora tardo-romana del tipus KEAY XXVI (Spatheion)"). En Un abocador del segle $v$ d.C. en el Forum provincial de Tarraco (Memorias de Excavació, 2). Tarragona.

Morales, A. et alii. (1993): «Plaza del Marqués: Aproximación arqueozoológica preliminar a la fauna recuperada en el asentamiento romano de Cimadevilla (Gijón, Asturias)». Bol. I.D.E.A., (e.p.).

Moreno, A., y ABAD, L. (1971): «Aportaciones al estudio de la pesca en la Antigüedad». Habis, 2. Sevilla.
Morloti, J. M. (1992): "Noticias de Arqueologia en Cantabria.Año 1992». Nivel Cero, 2. Santander.

MuñI/, O. (1979): El Mar. El Libro de Gijón. Gijón.

Navi:IRo, J. (1981): "As ánforas romanas de A Coruña (I)». Brigantium, 2. La Coruña.

NAVEtro. J. (1982): «As ánforas romanas de A Coruña (II))". Brigantium, 3. La Coruña.

NAvtiRo, J. (1991): El comercio antiguo en el N.W. peninsular. La Coruña.

NAvfiro, J., y Lópt/, F. (1992): «Un Finisterre atlántico en época romana: la costa galaica (NW de la península Ibérica)", en WOOD, M., y QUFIROGA, F.: Current Research on the Romanization of the Western Provinces (B.A.R.Int.Ser., 575). Londres.

Nonn, H. (1966): «L'Océan et les vents près dees côtes». Les Régions cotières de la Galice (Espagne). Etude Géomorphologique. Paris.

Pascual, R. (1968): "Acerca de la fabricación de ánforas». Ampurias, 30. Barcelona.

PIREIRA, G. (1983): Estudos de Cultura Castrexa $e$ de $H^{a}$ Antiga de Galicia. Santiago de Compostela.

Pérez Losada, F. (1988): «Noville (Franza, Mugardos, A Coruña)». Arqueoloxia. Informes, 2.

Pérez, C., e Illarregui, E. (1992): Algunas ideas sobre la romanización del Mar Cantábrico. Santiago de Chile.

Pérez, R., y Ortiz, J. (1987): Cantabria en la Alta Edad Media. Santander.

Ponsich, M. (1988): Aceite de oliva y salazones de pescado. Factores económicos de Bética y Tingitania. Madrid.

Posac, C., y Rodriguez Oliva, P. (1979): «La villa romana de Sabinillas (Manilva)». Mainake, 1. Málaga.

Púrpura, G. (1982): «Pesca e stabilimenti antichi per la lavorazione del pesce in Sicilia (III)". Sicilia Archeologica, 69; Trapani.

REDDE, M. (1979): «La navigation au large des côtes atlantiques». M.E.F.R.A., I. París.

Rosello, E. (1989): «Informe preliminar de la Ictiofauna de Santa Pola (Prov. Alicante)». Saguntum (PLAV), 22. Valencia.

Rouge, J. (1966): Recherches sur l'organisation du commerce maritime en Méditerranée sous l'empire romaine. Paris.

Ruiz-GÁlvez, M. (1986): «Navegación y comercio entre el Atlántico y el Mediterráneo a fines de la Edad del Bronce». Trabajos de Prehistoria, 43. Madrid.

Saenz, C., y Velez,J.(1974): La mineria primitiva del N.O. de España. Madrid. 
SANQtrR, R. (1973): «Une novelle lecture de l'inscription a Neptune trouvè à Douarnenez (Finistère) et l'industrie du garum armoricain». Annales de Bretagne, 30. Rennes.

Sanqufr, R, y Galluo, P. (1972): "Garum, sel et salaisons en Armorique gallo-romaine». Gallia,30. Paris.

Sangetr. R.; PIOt, R., y Gialiou, P. (1977): “Problèmes de navigation en Manche occidentale à l'époque romaine". Caesarodumum, 12 (Colloque sur la Géographie commerciale de la Gaule). París.

SENEN, F. (1980): «Arqueoloxia sobmariña: os materiais procedentes da badia coruñesa». Brigantium, 1. La Coruña.

Solana, J. M.*. (1977): Flaviobriga. Castro Urdiales. Santander.

Somoza, J. (1988): Cosiquines de la mio quintana. Gijón.

SPERBE.R, D. (1968): "Some observations of fish and fisheries in Roman Palestine». Zeitschrif der
Deutschen Morgenländischen Gesellschafi, 118 Wiesbaden.

T.I.R. (1991): Tabula Imperii Romani. Hoja K-29: Porto. (VV.AA.), Madrid.

Tobit, J. L., y Chansac, M. (1989): «Découvert d'une épitaphie du début de L’Empire Romain sur le site d'une usine de salaisons à Guéthary, Pyrénées-Atlantiques". Bull. Musée Basque (N. "Ex(ra). Bayonne.

VA/quiz SEIJAs, M. (1952): "Factorias pesqueras de la Playa de Area». Bol. Com. Monum. Lugo, 5,37/ 38. Lugo.

VAzQuh / VARELA, M. (1979): "La pesca en la Cultura Castreña de Galicia». Braña, 2.

VEGAA DE LA TORRE, J. R. (1982): «Numismática antigua de la provincia de Santander». Sautuola, 3. Santander.

VV.AA. (1860): Derrotero de la costa septentrional de España (partes / y II). Madrid. 